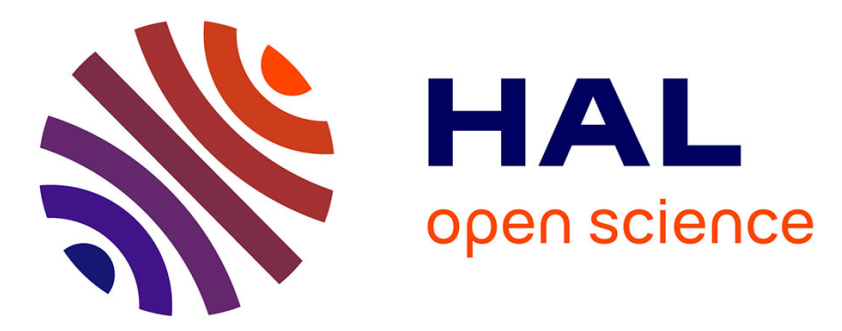

\title{
THE EFFECT OF DIFFERENT TRANSITION METALS ON THE RECOMBINATION EFFICIENCY OF DISLOCATIONS
}

T. Fell, P. Wilshaw

\section{- To cite this version:}

T. Fell, P. Wilshaw. THE EFFECT OF DIFFERENT TRANSITION METALS ON THE RECOMBINATION EFFICIENCY OF DISLOCATIONS. Journal de Physique IV Proceedings, 1991, 01 (C6), pp.C6-211-C6-216. 10.1051/jp4:1991632 . jpa-00250718

\section{HAL Id: jpa-00250718 https://hal.science/jpa-00250718}

Submitted on 1 Jan 1991

HAL is a multi-disciplinary open access archive for the deposit and dissemination of scientific research documents, whether they are published or not. The documents may come from teaching and research institutions in France or abroad, or from public or private research centers.
L'archive ouverte pluridisciplinaire HAL, est destinée au dépôt et à la diffusion de documents scientifiques de niveau recherche, publiés ou non, émanant des établissements d'enseignement et de recherche français ou étrangers, des laboratoires publics ou privés. 
JOURNAL DE PHYSIQUE IV

Colloque C6, supplément au Journal de Physique III, Vol. 1, décembre 1991

C6-211

\title{
THE EFFECT OF DIFFERENT TRANSITION METALS ON THE RECOMBINATION EFFICIENCY OF DISLOCATIONS
}

\author{
T.S. FELL and P.R. WILSHAW \\ Department of Materials, Parks Road, GB-Oxford OX1 3PH, Great-Britain
}

\begin{abstract}
MBE growth of $\mathrm{Si}_{1-\mathrm{X}} \mathrm{Ge}_{\mathrm{X}}$ on $(100) \mathrm{Si}$ substrates was used to produce $60^{\circ}$ misfit dislocation networks at depths suitable for EBIC investigation. Two different Ge concentrations were used to generate networks of different dislocation density. The effects of different transition metal contaminants on the recombination efficiency of the dislocations has been investigated for the different dislocation density layers. $\mathrm{Cu}, \mathrm{Fe}, \mathrm{Ni}$, and $\mathrm{Cr}$ metallic impurities were diffused into the specimens during a $\mathbf{3 0}$ minute anneal at $700^{\circ} \mathrm{C}$. EBIC images taken under identical experimental conditions have been qualitatively compared in order to assess the relative effects of each of these contaminants. Results of these investigations have indicated how, in all cases, the addition of metallic impurities increases the electrical activity of the dislocations with differences between the different metals being observed.
\end{abstract}

\section{Introduction.}

After many years of research into the electrical properties of dislocations in silicon the microscopic cause of their electrical activity is still not fully understood although in many cases it has been attributed to the presence of impurities decorating the dislocations $[1,2,3,4]$. Based on the hypothesis that the electrical activity and gettering efficiency of dislocations should be closely related and thus that recombination strength may be a measure of the impurity contamination at a defect, several authors have used EBIC as an "analytical" tool to investigate gettering at a variety of different dislocation and defect structures [5,6]. However, recent qualitative EBIC measurements[7], confirming the charge controlled model of recombination at dislocations in silicon [8], have shown that this commonly held view that the higher the concentration of impurities at dislocations the higher their recombination activity, is not always correct. The controlling factor which limits the maximum recombination strength at a dislocation is found to be the amount of charge induced band bending at the defect which is often determined by the position of the impurity induced defect state in the band gap and not the concentration of defect states [9]. As a result a small number of deep dislocation states may produce a higher level of recombination activity than a larger number of shallow states. This model however only remains valid for impurity decoration below the level required for precipitation at the dislocation in which case the activity may then be due to the precipitates themselves.

In the present work the effects of different transition metal contaminants on the recombination efficiency of well characterised $60^{\circ}$ dislocations have been investigated by comparing EBIC images taken under identical conditions. This method of comparison to infer the relative recombination efficiency of the dislocations is valid only if certain experimental criteria are fulfilled [10] i.e. if the defects investigated are all at the same depth the depletion region width remains constant, and the diffusion length is the same in each specimen investigated. The dislocations studied in this work were located at the epitaxial layer/substrate interface and thus for a given epitaxial layer the first two criteria are fulfilled for all dislocations. The method of $\mathrm{Wu}$ and Wittry [11] was used to make diffusion length measurements which were found to be approximately constant in each specimen after the introduction of the metallic impurities. Although as this method should ideally be performed on an area free of defects, it was not well suited to these specimens and therefore there is some doubt as to the accuracy of these measurements. However in the following analysis of these experiments any changes in the diffusion length between specimens are assumed not to be significant. The results obtained indicate differences in the recombination activity induced at the dislocations by the different metals. However this information does not allow conclusions to be drawn about the relative concentration of impurities at the dislocations for the reasons given above and, in particular, a high level of recombination activity does not necessarily imply a high dislocation affinity for the particular metallic impurity 
which had been introduced. In order to deduce fundamental dislocation parameters such as the position of the induced defect states in the band gap further quantitative measurements of the form described in $[7,8]$ are required.

\section{Experimental}

\subsection{Epitaxial Structure}

Dislocations in two different epitaxial structures have been investigated. Both structures consisted of a $0.25 \mu \mathrm{m}$ silicon buffer layer deposited onto a (100) silicon wafer substrate, followed by either a $1.6 \mu \mathrm{m} \mathrm{Si} 0.94 \mathrm{Ge} 0.06$ layer (layer S1073), or a $1.0 \mu \mathrm{m} \mathrm{Si} 0.95 \mathrm{Ge} 0.05$ layer (layer S776). These structures were deposited at growth temperatures of $625^{\circ} \mathrm{C}$ and $600^{\circ} \mathrm{C}$ respectively. In both these samples the SiGe layer thickness exceed the Matthews and Blakeslee [12] critical thickness at which relaxation of the lattice mismatch by the propagation of misfit dislocations becomes energetically possible. A detailed study of the nucleation and propagation of misfit dislocations in the $\mathrm{Si}_{1-\mathrm{X}} \mathrm{Ge}_{\mathrm{X}} / \mathrm{Si}$ system has been made by Tuppen et al [13]. They show the misfit dislocations to take the form of half-loops on $\{111\}$ planes which glide approximately symmetrically outwards from nucleation centres, along $<110>$ directions forming orthogonal cross grids in the plane of the strained interface. The interfacial segments of these half-loops are $60^{\circ}$ dislocations whilst those threading to the surface are screw dislocations as illustrated in figure 1. EBIC images of the screw, threading dislocation can be obtained using a low electron acceleration voltage $(10 \mathrm{kV})$ so that electrical activity in the near surface region of the epitaxial layer is highlighted. The threading dislocations are clearly visible as black dots in the EBIC micrograph of figure $2 \mathrm{a}$, and show a one to one correlation with the dislocations as revealed using a Schimmel etch and optical microscopy in figure $2 b$. The epitaxial layers were grown on a $\mathrm{n}+$ substrate and although nominally undoped were actually found to be $\mathrm{n}$-type. Capacitancevoltage measurements on a Au/Pd Schottky barrier deposited on these samples revealed doping concentrations in the epitaxial layers of $6.6 \times 10^{15} \mathrm{~cm}^{-3}$ for $\$ 1073$ and $4.0 \times 10^{15} \mathrm{~cm}^{-3}$ for $\$ 776$. In addition to this small difference in doping concentration, because of the differences in the germanium content and the thickness of the SiGe layer there is a higher dislocation density after annealing in S1073 than S776. The dislocation density in these two structures was revealed using a Schimmel etch and is shown in figures 3a and3b for the copper contaminated S1073 and S776 specimens respectively. Although in these figures the Schimmel etch has appeared to delineate individual dislocations, Tuppen et al [13] have shown that it is more likely that some of these etch lines represent a number of misfit dislocations lying very close together on the same slip plane. Copper precipitation can be observed in the micrograph of the $\mathbf{S 7 7 6}$ sample. These micrographs show that the dislocation density is too high to resolve all the individual dislocations using EBIC. Thus the features observed in the EBIC micrographs are most likely to be clusters of several dislocations on the same slip plane seen against a background of a more uniformly distributed lower density of individual dislocations. The average number of dislocations in a typical cluster is thought tobemore in the $\mathbf{S} 1073$ compared to the $S 776$ specimens.

Figure 1. Schematic diagram showing the interfacial $60^{\circ}$ segment and the threading screw segment of a misfit dislocation half-loop.

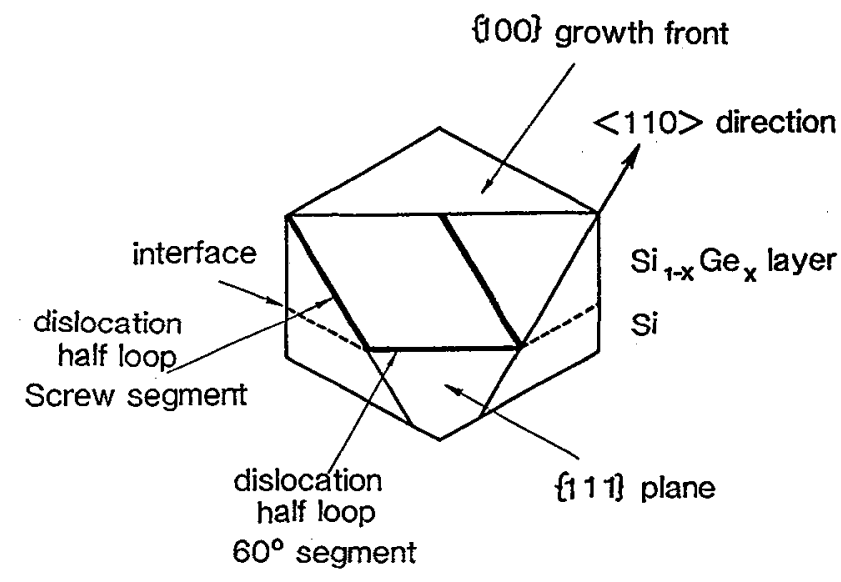




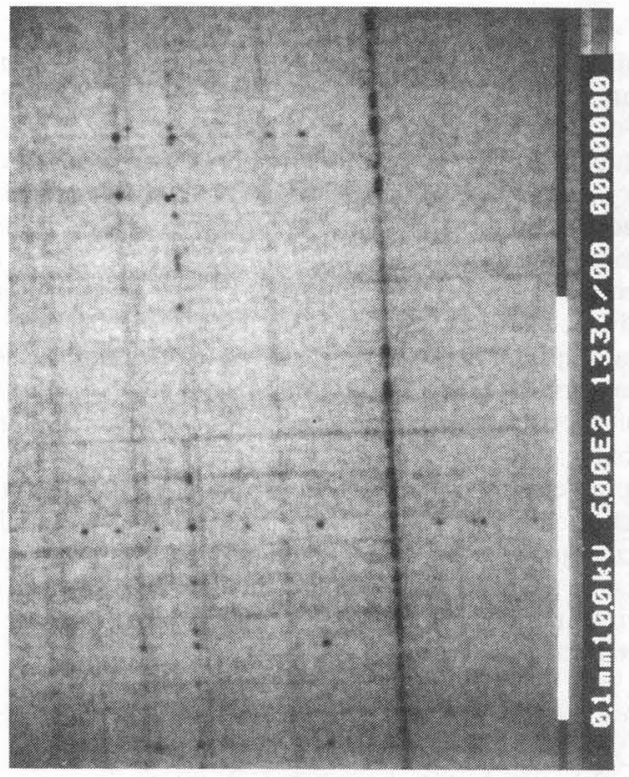

Figure 2a. An EBIC micrograph taken at $10 \mathrm{kV}$ showing threading dislocation segments intersecting the specimen surface.

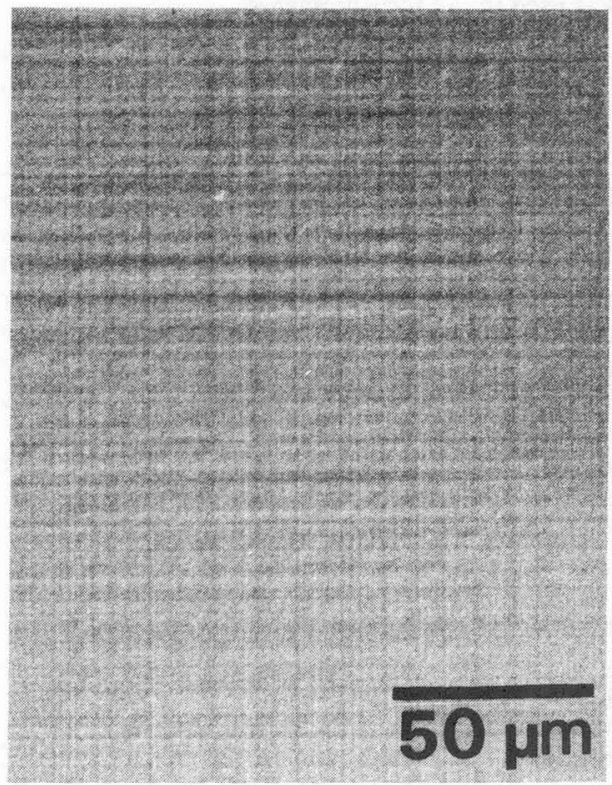

Figure 3a. An optical micrograph of copper contaminated S1073 material after been given a 30 second Schimmel etch to reveal the dislocation density.

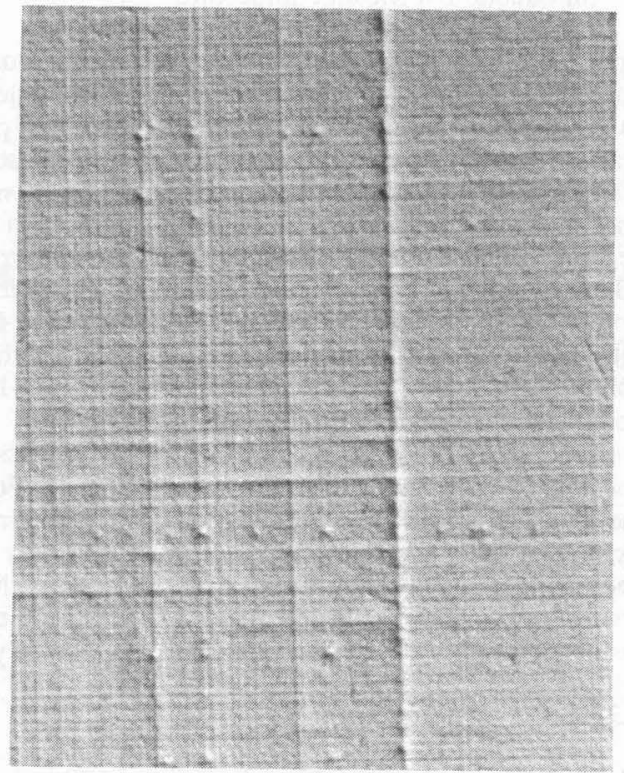

Figure $2 b$. An optical micrograph of the same area as 2a. taken after removing the Schottky barrier and highlighting the threading dislocations using a Schimmel etch.

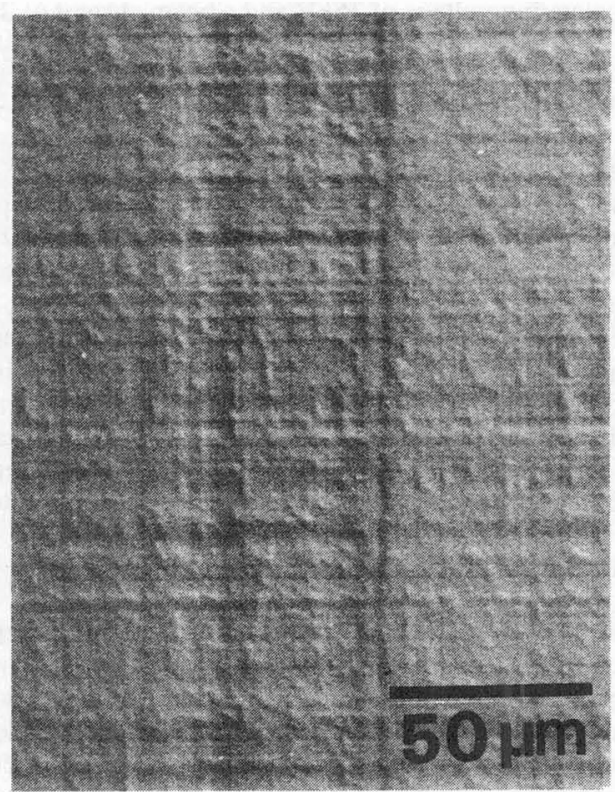

Figure 3b. A similar micrograph to $3 a$. but of the copper contaminated S776 material also showing copper precipitate etch features. 


\subsection{Introduction of Metallic Impurities}

Specimens were cleaved into $5 \mathrm{~mm}$ sided squares from the centre regions of each wafer. After cleaving and prior to contamination the specimens were given an RCA clean. To introduce the metallic contaminants the back surface of each specimen was wiped several times with either pure $\mathrm{Cu}, \mathrm{Fe}, \mathrm{Ni}$ or $\mathrm{Cr}$ wire or stainless steel tweezers. A double walled furnace was constructed form high purity fused quartz tubes in which a specimen could rest on a clean silicon wafer in a flow of nitrogen boiled off from a liquid nitrogen cryostat. Each specimen, including an uncontaminated specimen as a control, was individually annealed in this furnace for 30 minutes at a temperature of $700^{\circ} \mathrm{C}$ using a separate clean silicon wafer support each time. Prior to each anneal the inner furnace tube was cleaned with $48 \% \mathrm{HF}$ (BDH chemicals "Aristar grade"). Although the method of introducing the impurities is crude it is believed that only a very small amount of each impurity is actually introduced into the bulk silicon. This is because the amount introduced will not normally exceed the solid solubility of the impurity at the $700^{\circ} \mathrm{C}$ anneal temperature. These solubilities ranged from $\sim 2 \times 1010 \mathrm{~cm}^{-3}$ for $\mathrm{Cr}$ to $\sim 1 \times 1016 \mathrm{~cm}^{-3}$ for $\mathrm{Cu}$ [14]. These amounts are equivalent to the complete absorption of only small fractions of a surface monolayer of impurities. Such small impurity concentrations probably account for no precipitates being visible when a defect revealing etch was used on the specimens. The only exception was specimen S776 after copper contamination, see figure $3 b$. Indeed it is noted that considering how few impurity atoms are required to reach each element's solid solubility a strong possibility exists that other metallic impurities present in very low concentration in the "pure" metal sources may also have been unintentionally introduced in concentrations high compared to their solid solubility in silicon. However the control specimens showed that unless the specimens were intentionally wiped with metal no large increase in dislocation activity was observed. Thus any impurity introduced was actually coming from the metallic wire.

\subsection{EBIC Signal Collection}

The EBIC signal was collected using a $\sim 100 \AA$ thick Au/Pd Schottky barrier evaporated on the surface of each specimen. During the evaporation, which lasted 10 seconds, the specimen temperature did not rise above $100^{\circ} \mathrm{C}$. EBIC micrographs were taken using a system similar to one described previously [15] which is now based around a Philips 505 SEM with $\mathrm{LaB}_{6}$ gun. The brightness and contrast settings of the SEM CRT monitor used to generate the EBIC micrographs were not changed during the course of these investigations and the gain and offset settings of the phase sensitive detector were adjusted so that a given level of EBIC contrast produced the same change in output voltage and hence the same contrast in each of the micrographs after amplification of the EBIC signal. An accelerating voltage of $15 \mathrm{kV}$ and a beam current of $2 \times 10-11 \mathrm{~A}$ was used for all measurements.

\section{Results and Discussion}

EBIC micrographs showing the electrical activity at the uncontaminated annealed misfit dislocations and that resulting from the metallic contamination are presented in figure 4. After annealing without intentional contamination the dislocations in epitaxial layer S776 show no observable activity. However the dislocations in S1073 have been found to show activity both before and after the anneal. This may be due to residual impurities already present in this specimen. The slight increase observed after the anneal, giving typical contrast of $<2 \%$, may then be due to the large increase in dislocation density that occurs as the epitaxial layer relaxes above its growth temperature, together with further gettering of the impurities to these dislocations. Faintly visible denuded zones, producing a "halo" effect around the dislocations are observed in micrographs of this specimen. This appears to indicate that gettering has taken place. This effect was not observed in the intentionally contaminated specimens. In all cases however, the addition of metallic impurities is seen to increase the dislocation activity and notable differences are observed between the two epitaxial structures.

\subsection{Comparison of the Effect of Different Metals.}

The relative effects of $\mathrm{Ni}, \mathrm{Cr}, \mathrm{Fe}$ and stainless steel contamination are similar for each type of epitaxial layer. In each case $\mathrm{Ni}, \mathrm{Cr}$, and $\mathrm{Fe}$ showed similar levels of contrast ( $\sim 6-10 \%$ for layer S1073) and the stainless steel showed higher contrast ( $10-20 \%$ for layer S1073). The copper contaminated dislocations in layer S1073 showed 3-4\% contrast which was lower than for the other impurities. In addition the distribution of contrast along the dislocation lines was less homogeneous then for the other metals. The reason for this different spatial variation of EBIC contrast is not understood. If the charge controlled model for recombination is applicable to the dislocations without precipitates the above results could indicate that the copper impurity levels are less deep than those of $\mathrm{Fe}, \mathrm{Ni}$ and $\mathrm{Cr}$. The copper contaminated dislocations in layer S776 showed higher contrast, (12\%), than dislocations decorated with other impurities in the same specimen type. In this case the activity along the dislocation appears extremely nonuniform and Schimmel etching revealed features consistent with copper precipitate colonies [16]. It is thus inferred that when precipitation takes place at the dislocations recombination at the precipitates leads to an increased EBIC contrast at the precipitate/dislocation complex. 
S1073
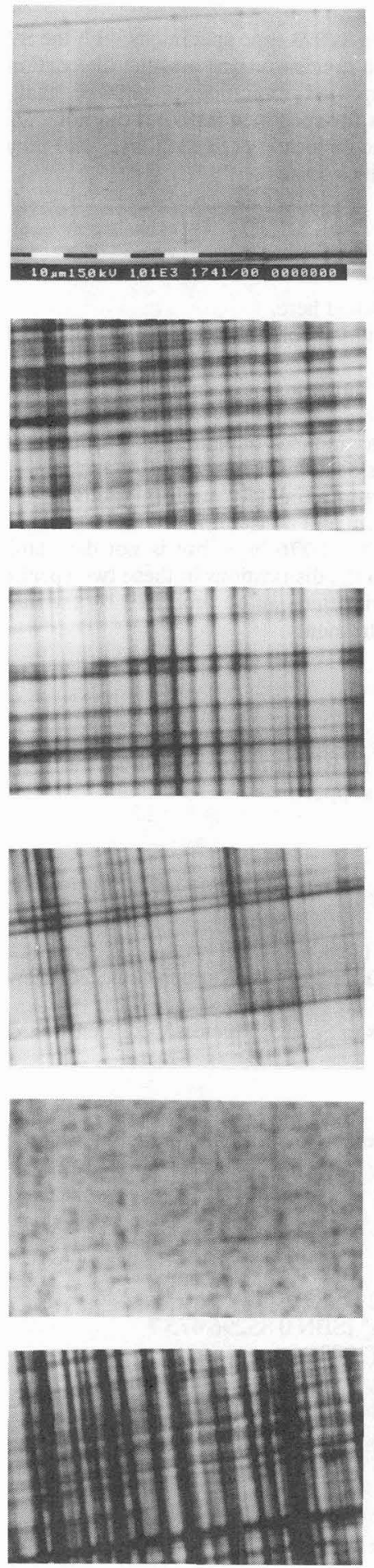

S776

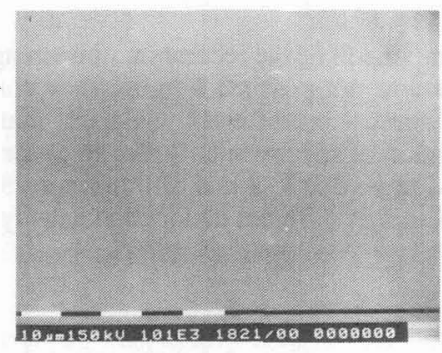

Ni

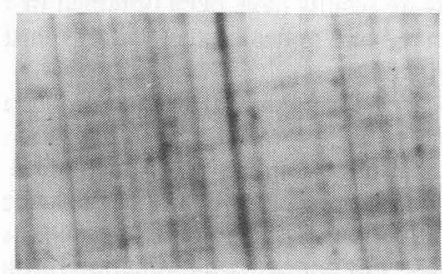

Cr
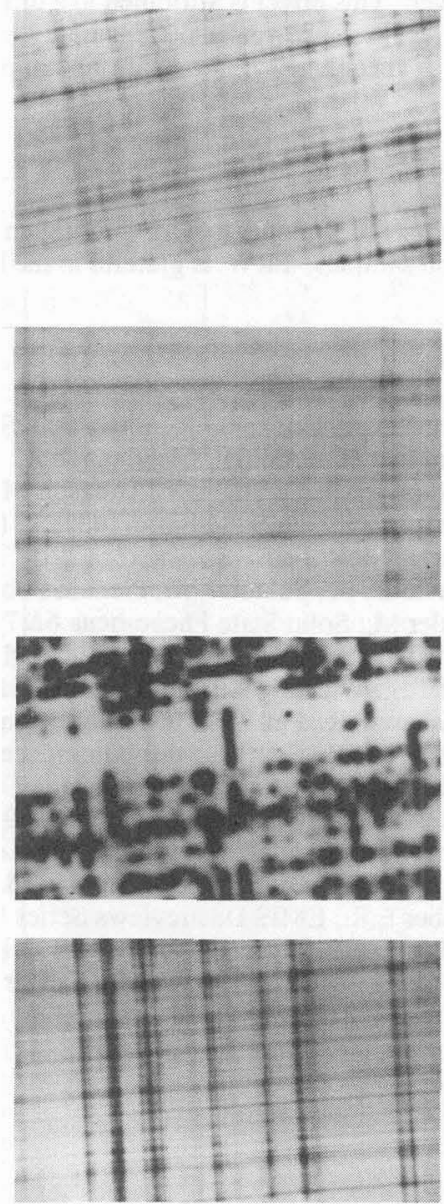

Figure 4. EBIC micrographs taken under identical conditions showing the electrical activity of the misfit dislocations in S1073 and S776 material after uncontaminated and metal contaminated anneals. 


\subsection{Comparison of the Two Epitaxial Layers}

Direct comparison of the recombination strength of the dislocations in the S1073 type specimens with the S776 type specimens was not possible because they contained different dislocation concentrations and the dislocations lay at different depths in differently doped material. However many repeated experiments showed that copper contamination of specimen S776 led to observable precipitation whereas for specimen S1073 it did not. This result is believed to be due to a real difference in the gettering efficiency of the dislocations in each layer and may be due to such factors as different dislocation density, residual strain and layer thickness.

\section{Summary}

The following results have been obtained from the misfit dislocations studied here.

a) As received and annealed dislocations in the specimens without intentional contamination show little, $<2 \%$, or no EBIC contrast.

b) In all cases the addition of metallic impurities has been found to increase the recombination activity of the dislocations.

c) $\mathrm{Ni}, \mathrm{Cr}, \mathrm{Fe}$ and stainless steel decoration of these misfit dislocations induces a higher level of recombination activity than that produced by copper provided no precipitation at the dislocations is observed.

d) Contamination with $\mathrm{Fe}, \mathrm{Ni}, \mathrm{Cr}$ and stainless steel resulted in approximately uniform activity along the dislocations. For copper contamination the activity was markedly different and non-uniform.

e) Copper precipitation has been found to occur at the dislocations in the $\$ 776$ layer but is not detectable in the S1073 layer. This effect is attributed to a difference in gettering between the dislocations in these two specimens.

f) These results, once again, demonstrate the amount of electrical activity that can be produced by the inadvertent handling of specimens with metallic, and in particular, stainless steel instruments.

Acknowledgements

The authors are grateful to Dr. C. Tuppen and Dr. C. Gibbings of BTRL Ltd. for providing the MBE misfit dislocation samples. PRW is grateful to the Royal Society for financial support.

\section{References}

[1] Ourmazd A., Booker G.R.; Phys. Stat. Sol. (a) 55, 771 (1979)

[2] Menniger H., Raidt H., Gleichmann R.; Phys. Stat. Sol. (a) 58, 173 (1980)

[3] Lightowlers E.C., Higgs V., Gregson M.J., Davis G., Davey S.T. ,Gibbings C.J., Tuppen C.G., Scaffler F., Kasper E.; Thin Solid Films 183, 235 (1989)

[4] Wilshaw P.R, Fell T.S., Booker G.R.; " Point and Extended Defects in Semiconductors", ed. Benedek G., Cavallini A., Schroter W., Plenum Publishing Corp. 243 (1989)

[5] Kittler M.; Solid State Phenomena 6\&7, 367 (1989)

[6] Battistella F., Rocher A.; Semicond. Sci. Technol. 2, 226 (1987)

[7] Fell T.S., Wilshaw P.R.; to be published, Inst. Phys. Conf. Ser., Microscopy of Semiconducting Materials 1991

[8] Wilshaw P.R., Fell T.S.; Inst. Phys. Conf. Ser. 104, 85 (1989)

[9] Wilshaw P.R., Fell T.S.; this conference

[10] Wilshaw P.R.; Ultramicroscopy 31, 177 (1989)

[11] Wu C.J., Wittry D.B.; J. Appl. Phys. 49(5), 2827 (1978)

[12] Mattews J.W., Blakeslee A.E.; J. Crystal Growth 27, 118 (1974)

[13] Tuppen C.G., Gibbings C.J., Hockly M.; J. Crystal Growth 94, 392 (1989)

[14] Weber E.R.; EMIS Datareviews Series No.4, "Properties of Silicon" ISBN 0852964757

[15] Wilshaw P.R., Ourmazd A., Booker G.R., J. Physique 44, C4-445 (1983)

[16] de Coteau M.D., Wilshaw P.R., Falster R.; Phys. Stat. Sol. (a) 117, 403 (1990) 